\title{
Reversal of Jaundice in Two Patients with Inoperable Cholangiocarcinoma Treated with Cisplatin and Gemcitabine Combination
}

\author{
Maarten Criel, ${ }^{1,2}$ Filip Geurs, ${ }^{1,2}$ Siegfried Ponette, ${ }^{1,2}$ Katrien Bulte, ${ }^{1,2}$ and Johan Ponette ${ }^{1,2}$ \\ ${ }^{1}$ Department of Medical Oncology, Regionaal Ziekenhuis SINT MARIA, Ziekenhuislaan 100, 1500 Halle, Belgium \\ ${ }^{2}$ Department of Gastroenterology, Regionaal Ziekenhuis SINT MARIA, Ziekenhuislaan 100, 1500 Halle, Belgium
}

Correspondence should be addressed to Filip Geurs, f.geurs@regzhsintmaria.be

Received 30 November 2011; Accepted 17 January 2012

Academic Editors: F. Pérez Roldán and H. Uchiyama

Copyright (C) 2012 Maarten Criel et al. This is an open access article distributed under the Creative Commons Attribution License, which permits unrestricted use, distribution, and reproduction in any medium, provided the original work is properly cited.

\begin{abstract}
Two patients are presented with severe jaundice, due to inoperable cholangiocarcinoma. The chemotherapeutic approach in patients with severe jaundice is discussed. Many schedules of chemotherapy were developed in this tumor type with normal serum bilirubin. We report here the first successful use of cisplatin and gemcitabine combination chemotherapy in these patients. Tolerability was good and liver function tests gradually improved.
\end{abstract}

\section{Introduction}

The increase in number of patients with cholangiocarcinoma poses specific problems for the diagnostic strategy as well as for an increasing need for specific therapy [1]. The aggressive nature as well as its localisation of the tumor causes its typical presentation with jaundice. Its lack of operative options requires often a chemotherapeutic approach [2]. However, little is known about the use of chemotherapy in jaundiced patients.

\section{Case Reports}

Patient A, 67-year-old Caucasian, presented with jaundice and was found at laparoscopy to have multiple intrahepatic metastases (Figure 1). Biopsy showed cholangiocarcinoma. Because of jaundice that could not be relieved surgically, the patient was transferred to the medical oncology ward. Because of the bilirubin level of $3.58 \mathrm{mg} / \mathrm{dL}$ at admission, we started with a lower dose of gemcitabine $800 \mathrm{mg} / \mathrm{m}^{2}$ on day 1 and cisplatin $25 \mathrm{mg} / \mathrm{m}^{2}$. Bilirubin level dropped at day 4 allowing for an increase of gemcitabine to $1 \mathrm{~g} / \mathrm{m}^{2}$ on day 8 . Subsequent chemotherapies were done on an outpatient basis (gemcitabine $1 \mathrm{~g} / \mathrm{m}^{2}$ days $1+8$ and cisplatin $25 \mathrm{mg} / \mathrm{m}^{2}$ days $2+9 \mathrm{q} 3 \mathrm{w}$ ). Liver test all normalised (Figure 2) and CA
19.9 almost normalised. After 8 months of treatment, ascites developed due to progressive neoplastic disease, and patient subsequently received hospice care and died 10 months after diagnosis.

Patient B is a 67-year-old housewife, who presents with progressive jaundice (bilirubin of $16 \mathrm{mg} / \mathrm{dL}$ ) due to an underlying neoplasm of the bile duct (Klatskin type 1). CT scan showed intrahepatic metastases (Figures 3 and 4), and liver biopsy showed cholangiocarcinoma. After Ercp and stenting, bilirubin remained elevated at $3.2 \mathrm{mg} / \mathrm{dL}$. Chemotherapy with gemcitabine-cisplatin (initially $800 \mathrm{mg} / \mathrm{m}^{2}$ on day 1 and $1 \mathrm{~g} / \mathrm{m}^{2}$ on day 8 , followed by cisplatin $25 \mathrm{mg} / \mathrm{m}^{2}$ on days 2 +9) was administered without any significant toxicity. Liver function tests normalised, and CA 19.9 dropped ten fold (Figure 5). The control CT-scan after six months of treatment showed partial response; the patient was referred for liver surgery, and she is awaiting a right hepatectomy (Figure 6).

For localized cholangiocarcinoma, a multitude of treatments [3] were developed. Maximal surgery, included extensive resections and liver transplants, was developed in reference centers [4]. Local treatment comprising endoprosthesis in the biliary tract and local photodynamic treatment relieves jaundice and bile duct compression [5-7]. Also combined chemotherapy and radiotherapy are reported [8]. 


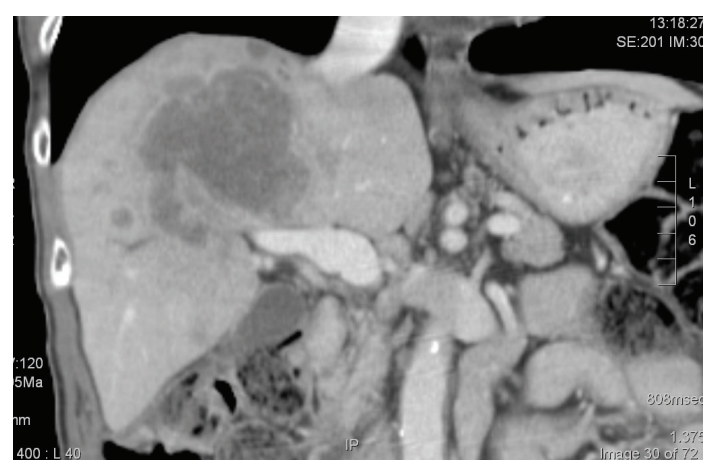

Figure 1: Initial CT scan in patient A, showing central cholangiocarcinoma with multiple satellite nodules surrounding the primary tumor.

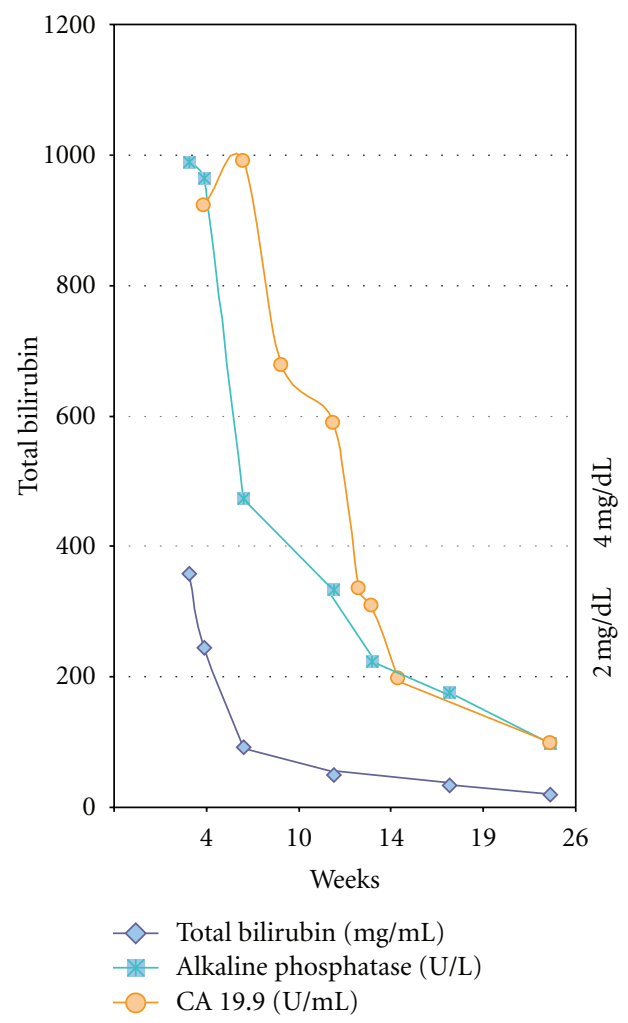

Figure 2: Evolution of liver function tests and tumor marker (CA 19.9) in patient $\mathrm{A}$.

Chemotherapy represents the cornerstone of management for patients with inoperable cholangiocarcinoma [9]. The literature on chemotherapy in advanced cholangiocarcinoma is difficult to interpret because of the heterogeneity of cholangiocarcinoma, the use of various chemotherapeutic agents in different combinations and dosing regimens, and the small size of existing patient cohorts [10]. A combination of cisplatin and gemcitabine is, according to the most recent phase 3 trial [11], the only effective treatment at hand. Other smaller series report on the use of oxaliplatin, capecitabin, and 5 fluorouracil $[12,13]$. All these combinations are, however, only published with normal heart and renal function

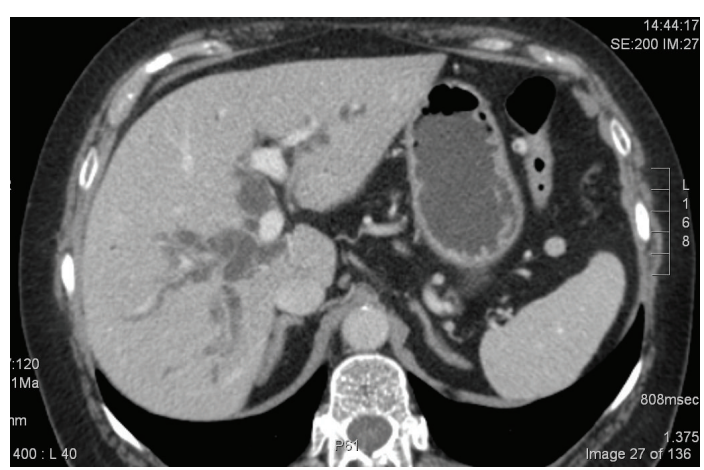

FIGURE 3: Impressive bile duct dilatation in patient B before stenting.

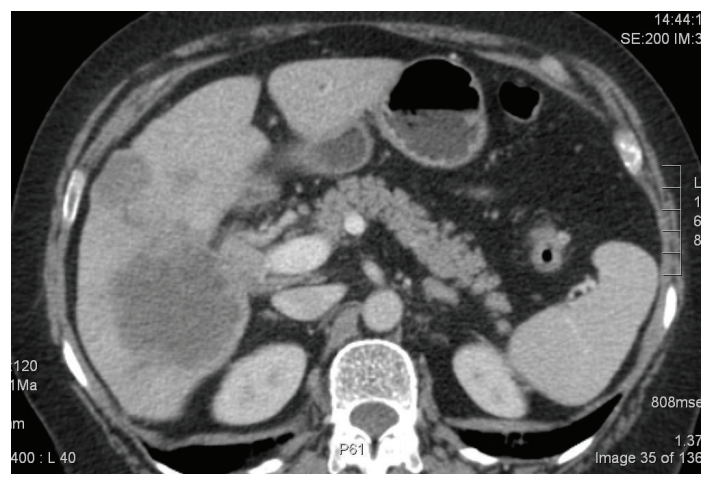

FIGURE 4: The underlying cholangiocarcinoma with intrahepatic metastasis and hilar extension in patient $\mathrm{B}$.

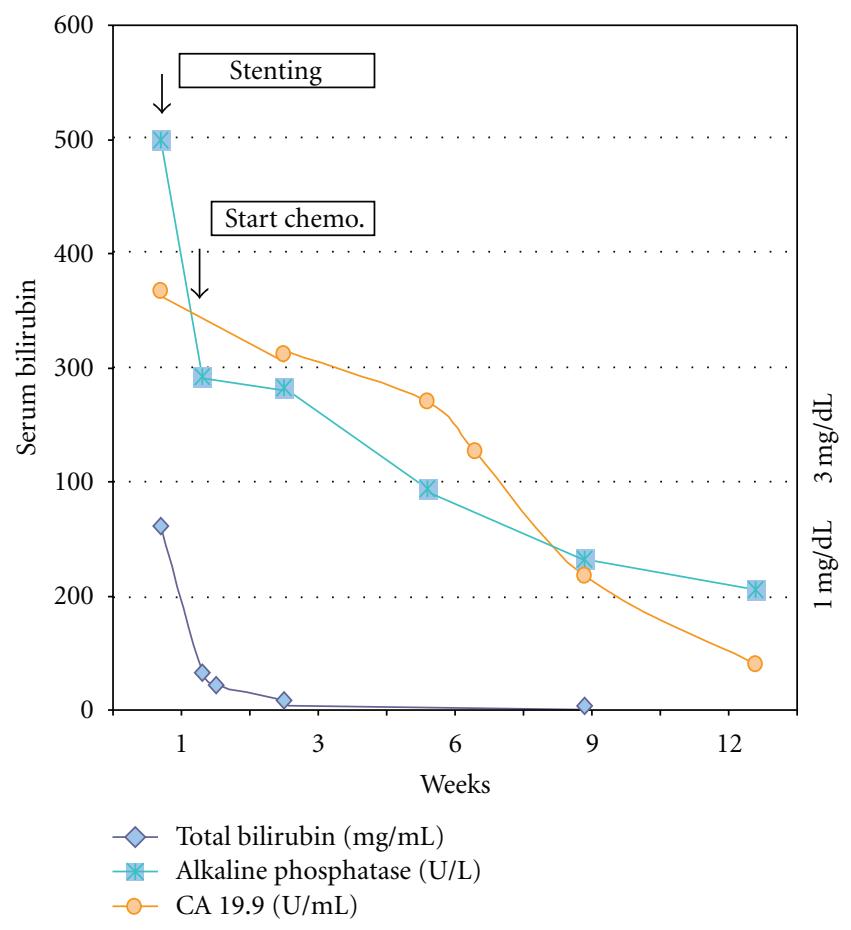

FIGURE 5: Evolution of liver function test and tumormarker (CA 19.9) in patient B. 


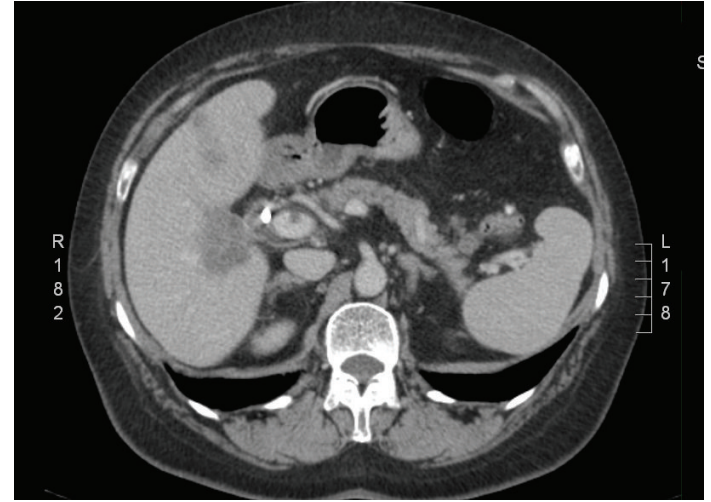

Figure 6: Partial response of the enormous mass in the right liver lobe.

and notably, bilirubin level below $2 \mathrm{mg} / \mathrm{dL}$. Most patients, even after stenting, present with bilirubin levels over $2 \mathrm{mg} / \mathrm{dL}$ $[14]$ as was the case in our second patient. This illustrates the lack of data in patients with end organ failure, notably liver failure and jaundice, like we previously reported [15].

Although gemcitabine-cisplatin combination represents the most accepted chemotherapy regimen for biliary cancers at present, very few studies so far have looked at the feasibility and results in cholangiocarcinoma patients with jaundice. The initial doses of gemcitabine we used in both patients $\left(800 \mathrm{mg} / \mathrm{m}^{2}\right)$ represent a $20 \%$ reduction of the maximally tolerated dose of $1 \mathrm{~g} / \mathrm{m}^{2}$ [11] but retains significant effectiveness and is therefore also used in elderly patients with bladder cancer. The weekly use of cisplatin at $35 \mathrm{mg} / \mathrm{m}^{2}$, two weeks out of three, is safe and effective as we have shown in another patient series with cisplatin monotherapy in severe jaundice [15].

\section{Conclusion}

We demonstrated in two patients with severe jaundice due to metastatic cholangiocarcinoma that cisplatin and gemcitabine combination chemotherapy can be safely and effectively administered. Both patients had similar response and tolerance as in patients with normal bilirubin.

\section{References}

[1] B. Blechacz, M. Komuta, T. Roskams, and G. J. Gores, "Clinical diagnosis and staging of cholangiocarcinoma," Nature Reviews Gastroenterology and Hepatology, vol. 8, no. 9, pp. 512-522, 2011.

[2] C. D. Anderson, C. W. Pinson, J. Berlin, and R. S. Chari, "Diagnosis and treatment of cholangiocarcinoma," Oncologist, vol. 9, no. 1, pp. 43-57, 2004.

[3] T. Tajiri, H. Yoshida, Y. Mamada, N. Taniai, S. Yokomuro, and Y. Mizuguchi, "Diagnosis and initial management of cholangiocarcinoma with obstructive jaundice," World Journal of Gastroenterology, vol. 14, no. 19, pp. 3000-3005, 2008.

[4] I. De Vreede, J. L. Steers, P. A. Burch et al., "Prolonged disease-free survival after orthotopic liver transplantation plus adjuvant chemoirradiation for cholangiocarcinoma," Liver Transplantation, vol. 6, no. 3, pp. 309-316, 2000.

[5] H. Witzigmann, F. Berr, U. Ringel et al., "Surgical and palliative management and outcome in 184 patients with hilar cholangiocarcinoma: palliative photodynamic therapy plus stenting is comparable to R1/R2 resection," Annals of Surgery, vol. 244, no. 2, pp. 230-239, 2006.

[6] Y. K. Cheon, "The role of photodynamic therapy for hilar cholangiocarcinoma," Korean Journal of Internal Medicine, vol. 25, no. 4, pp. 345-352, 2010.

[7] J. A. Richter and M. Kahaleh, "Photodynamic therapy: Palliation and endoscopic technique in cholangiocarcinoma," World Journal of Gastrointestinal Endoscopy, vol. 2, no. 11, pp. 357361, 2010.

[8] T. B. Brunner and C. L. Eccles, "Radiotherapy and chemotherapy as therapeutic strategies in extrahepatic biliary duct carcinoma," Strahlentherapie und Onkologie, vol. 186, no. 12, pp. 672-680, 2010.

[9] F. Eckel, T. Brunner, and S. Jelic, "Biliary cancer: ESMO clinical practice guidelines for diagnosis, treatment and follow-up," Annals of Oncology, vol. 22, supplement 6, pp. vi40-vi44, 2011.

[10] M. J. Kim, D. Y. Oh, S. H. Lee et al., "Gemcitabine-based versus fluoropyrimidine-based chemotherapy with or without platinum in unresectable biliary tract cancer: a retrospective study," BMC Cancer, vol. 8, article no. 374, 2008.

[11] J. Valle, H. Wasan, D. H. Palmer et al., "Cisplatin plus gemcitabine versus gemcitabine for biliary tract cancer," New England Journal of Medicine, vol. 362, no. 14, pp. 1273-1281, 2010.

[12] O. Nehls, H. Oettle, J. T. Hartmann et al., "Capecitabine plus oxaliplatin as first-line treatment in patients with advanced biliary system adenocarcinoma: a prospective multicentre phase II trial," British Journal of Cancer, vol. 98, no. 2, pp. 309315, 2008.

[13] A. K. Charalabopoulos, S. P. Krivan, N. A. MacHairas, E. P. Misiakos, and A. N. MacHairas, "Endopancreatic bile duct cholangiocarcinoma in a patient with peutz-jeghers syndrome," HPB Surgery, vol. 2011, Article ID 364570, 4 pages, 2011.

[14] N. Razumilava and G. J. Gores, "Combination of gemcitabine and cisplatin for biliary tract cancer: a platform to build on," Journal of Hepatology, vol. 54, no. 3, pp. 577-578, 2011.

[15] M Gabrovska, F Geurs, S Ponette et al., "Weekly cisplatin may reverse liver dysfunction and jaundice caused by diffuse liver metastases of solid tumors," Hepatic Medicine: Evidence and Research, vol. 1, pp. 9-12, 2009. 


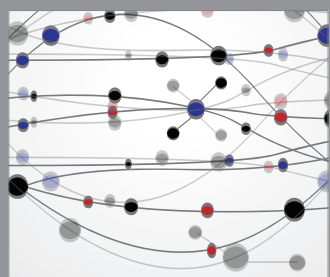

The Scientific World Journal
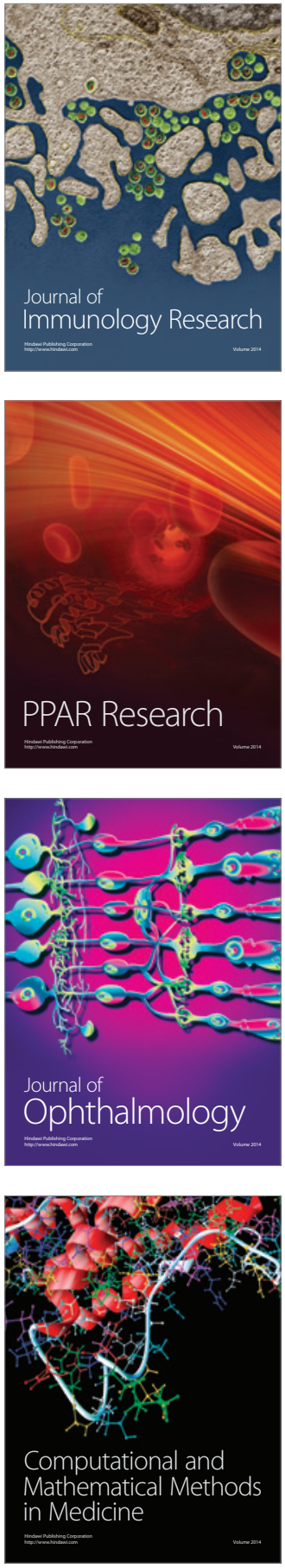

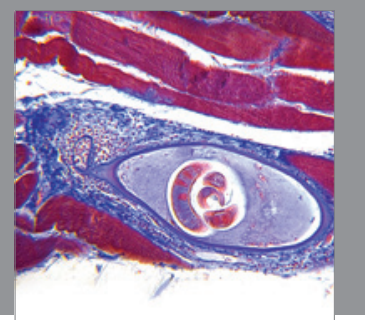

Gastroenterology

Research and Practice
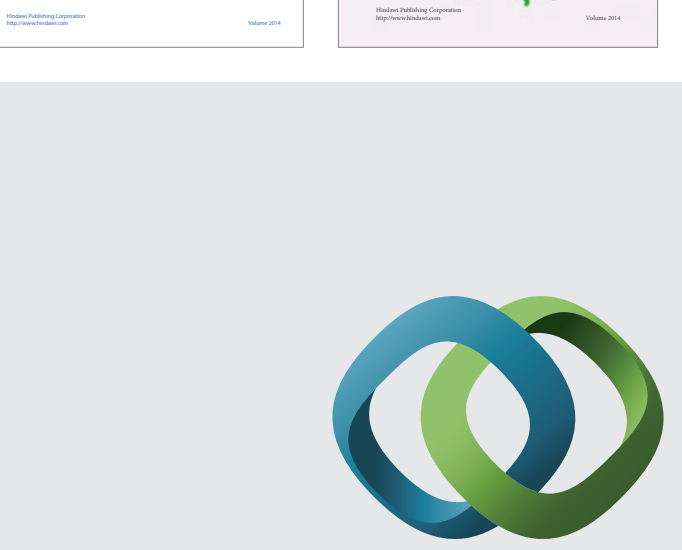

\section{Hindawi}

Submit your manuscripts at

http://www.hindawi.com
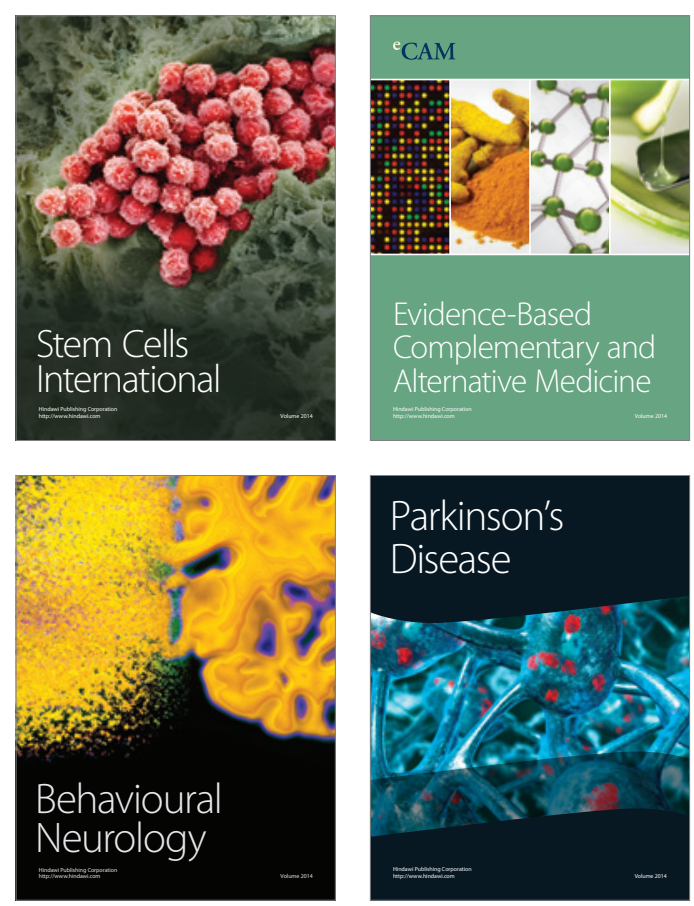

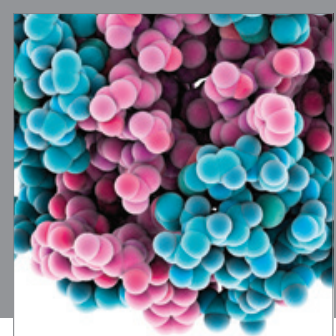

Journal of
Diabetes Research

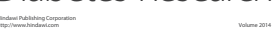

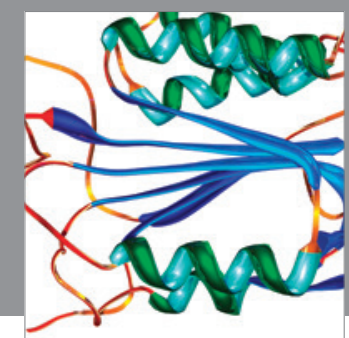

Disease Markers
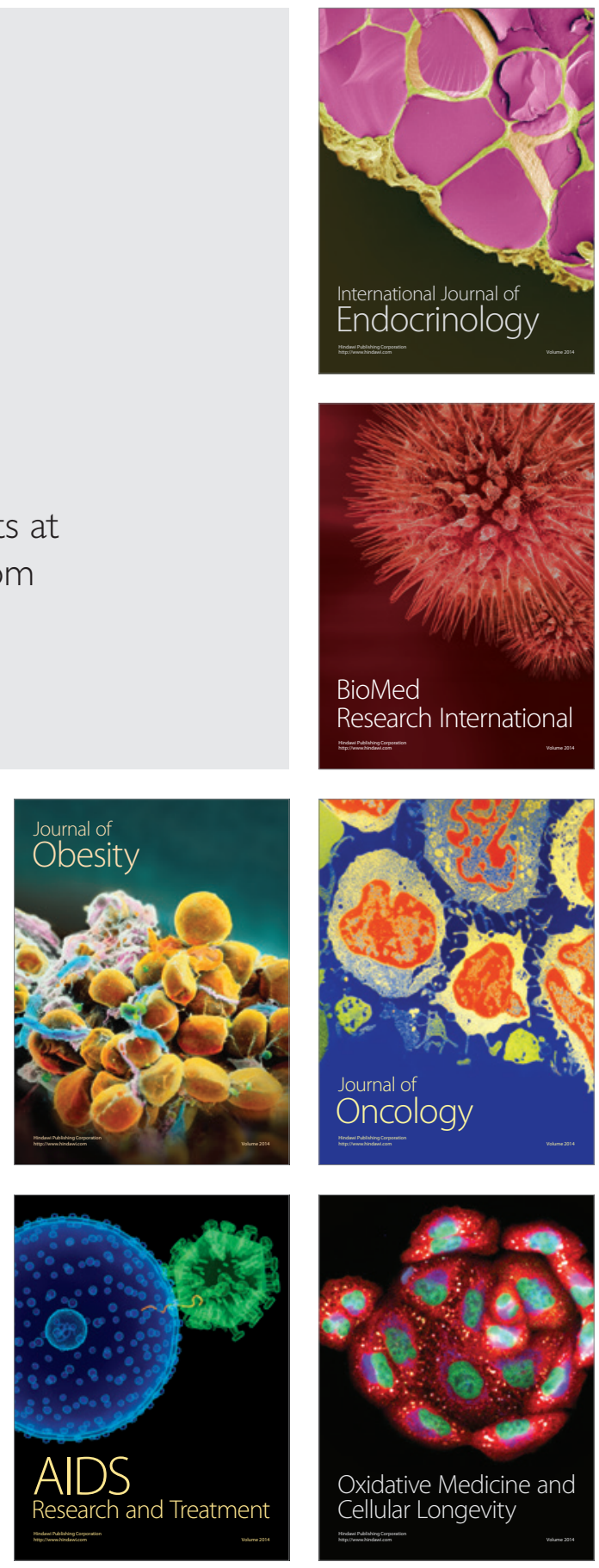